\title{
Introduction: Special Issue: Alcohol and Leisure, Sport and Tourism
}

\section{Catherine Palmer ${ }^{1}$}

Accepted: 22 December 2020 / Published online: 26 January 2021

(C) The Author(s), under exclusive licence to Springer Nature Switzerland AG part of Springer Nature 2021

\section{Introduction}

As the world grapples with the COVID-19 pandemic, leisure has taken on new significance. Major sporting events have been cancelled, rescheduled or reimagined for a new "COVID normal". Almost all places outside our homes - restaurants, pubs, bars and nightclubs, swimming pools, gyms, arts venues, theatres, cinemas, museums and galleries - are not open. Playground equipment is taped off and parks and beaches are closed too. In only a matter of months, the COVID-19 pandemic raised questions about what we value and why. What, then, is the importance (or not) of leisure in this crisis?

At the same time, alcohol use and misuse has taken on a particular importance as we wrestle with the ways in which the pandemic has either introduced new or exacerbated old problems associated with alcohol consumption especially for vulnerable people and people in regional communities. The ready accessibility of home delivery, the absence of checks-and-balances in online purchases, and the ability to consume alcohol at home without monitoring, all present a set of challenges for those struggling with addiction and mental health, exacerbated by job lay-offs, with sportsworkers a key, but largely ignored, group. As alcohol consumption and production increases in a range of cultural contexts and settings, so to does academic interest by sociologists and other social scientists of leisure, sport and tourism.

Against this background, the significance of critical perspectives for understanding many aspects of alcohol and its relationships to leisure, sport and tourism has become more acute. As a broad field bringing together a diverse range of theoretical and methodological stand points, the sociology of leisure provides a set of perspectives on this current moment, particularly the impacts on sociality across individual and community experiences of sport, leisure and tourism.

While the special issue was not commissioned to address or speculate on the implications of COVID-19 on leisure, sport and tourism, the pandemic casts an

Catherine Palmer

Catherine.Palmer@utas.edu.au

1 School of Social Sciences, University of Tasmania, Hobart, Australia 
unavoidable shadow over sport, leisure and tourism. Several of the papers assembled were written pre-COVID, others were submitted just as the pandemic hit. All, in different ways, provide critical commentary on the sociality of leisure and alcohol (including social inequalities) across a range of geographical and empirical settings; the implications of which COVID-19 has brought into sharp relief. As the papers variously note, while drinking is central to a range of forms of socialisation and transitions in sport, leisure and tourism that are immensely pleasurable, they are also problematic, indicative of and leading to a range of social concerns of relevance to the sociology of leisure, sport and tourism. The special issue then continues an ongoing research agenda (Palmer 2013) that asks sociologists to extend our conceptual, theoretical and empirical frameworks for thinking about drinking in the context of leisure, sport and tourism.

\subsection{Scope and Content}

With a focus on the role of drinking settings in the production and reproduction of sociality, several of the papers conceptualise 'drinking destinations' as places of leisure, sociability and belonging. Borrowing from Bell's (2008) notion of "alcotourism" which brings together studies of tourism and studies of alcohol consumption to include practices of travelling to drink, drinking on holiday, drinking to travel and drinking while travelling, Carlisle and Ritchie's (2020) paper re-examines the traditional party tourism enclaves frequented by British tourists. Noting that excessive alcohol consumption is an expected holiday behaviour at (primarily) beach destinations, they shift their analysis to assess the power of place and representations of excessive drinking via media and holiday discourses. Drawing from sociology and human geography, they apply notions of embodiment of space, liminality, and "wild and mephitic escapism" (2020, p. 1) to party tourism. Here, the authors point to a need to reposition analyses of destination drinking to explore the holistic reality of party enclaves so as to consider the such experiential realities amidst the role of the leisure industries in promoting alcohol consumption and the levels of governance and policing within the party tourism destination. Such a multi-layered analysis highlights the tensions inherent in the wider articulations of the pleasurable and problematic relationships between tourism, alcohol and social identities.

Turning to the burgeoning craft beer industry, Graefe and Graefe (2020) explore how people participate in the craft beer scene, questioning the production of new attachments, drinking styles, lifestyle norms, taste, inclusion and social diversity in craft beer culture. Arguing that the consumption of craft beer is an important component of travel and tourism (another variant of destination drinking) and, for some, may even represent the primary reason for leisure travel, the authors illustrate the way in which gender interacts with craft beer-related travel and tourism among Pennsylvania craft beer patrons. With a focus on a local industry with global reach - the craft sector is conservatively valued at $\$ 604 \mathrm{~m} \mathrm{pa}$, and has been growing at around $9 \%$ a year - (IbisWorld n.d.), the paper explores how commitments to community, locality and creativity are elaborated in pursuit of 'good beer'. The authors position the craft industry as one shifting away from beer's traditional associations 
with hegemonic masculinity to one attracting a gender and socially diverse community of consumers pursuing craft beer for leisure and pleasure. The local Pennsylvania setting also serves to locate the research in broader concerns with environmental activism and localism in contemporary cultural practices.

Thomas Thurnell-Read's (2020) paper was submitted just as the pandemic hit. While his is not intended as a commentary on COVID-19, it does offer a timely reflection on the ways in complex social upheavals can disrupt the rhythm of cultural life. With some parallels with Graefe and Graefe's paper, Thurnell-Read (2020) examines how some pubs have navigated economic precarity by shifting away from a 'wet led' focus on mass-produced alcohol brands towards a focus on quality, provenance and innovation espoused by the craft beer movement. Building on his previous research (Thurnell-Read 2016), the author describes the ways in which pubs serve as sites of pleasurable and meaningful social interaction, where locals engage in talk and "banter". Taking Wright Mills' (1959) concept of the sociological imagination, which makes the locus of sociological inquiry the interplay of personal troubles ('biography') and public issues ('history'), Thurnell-Read (2020) conceptualises the changing fortunes of the pub as a place of leisure, sociability and belonging. In doing so, he shows how past memories and recollections of pub going (by pub goers) are inflected through the changing social, cultural, economic and political contexts within which the British pub is located. Thurnell-Read (2020) concludes by restating the importance of conceptual and methodological orientations to the study of leisure that are equipped to explore and explain how the personal and the public are bound up in social change over time.

The importance of telling stories, banter and sharing tales of drinking is a theme pursued by Palmer et al. (2020). In their study of narratives of drinking among French climbers and older Australian athletes, Palmer et al. (2020) note that drinking talk in sport is an important means of sharing and shaping identity that speaks to the ritual functions of sociality and celebration. The authors note that "drinking talk" is an important source of membership and belonging among two contrasting sporting communities where 'having a story to tell is an opportunity to display and sustain their sense of identity both as friends and as followers of a particular sporting team' (2020, p. 20). More critically, they note that the shared humour and sociality of drinking - conveyed through the narratives and stories of drinking - emerged as being unexpectedly significant for the research corpus on alcohol and sport.

The importance of shared humour and drinking rituals in sport builds on the ideas of micro-sociology, and the focus on face-to-face interactions and behaviour in groups. The importance of face-to-face story telling has been compromised by COVID-19 and it remains to be seen the extent to which digital rituals of drinking and storytelling can operate with the same "collective effervescence" that Palmer et al. note. Extending Randall Collins' (Collins 2016) notions of the micro-sociology of interactions, Spaaij and Schaillée (2020) (via Erving Goffman) apply the concept to other work on interaction rituals in sport that offers points of resonance here. Spaaij and Schaillée (2020) along with Palmer et al. (2020) are equally attentive to the inherently social nature of the dynamics of leisure production and consumption across a range of geographical and empirical contexts. 
Continuing the orienting theme of the sociality of sport, leisure and tourism, Sarah Gee, Rachel Batty and Patti Millar extend the focus on micro-interactions to an analysis of alcohol sponsorship of sport in New Zealand. Taking a proposed ban on alcohol sponsorship of sport, especially rugby, as their point of departure, they argue that, notwithstanding the potential for such a ban to help reduce alcohol related harm, such debates need to be positioned in a broader discission of the economic risks (for clubs) alongside the social connections between rugby clubs and cultural and civic life. With parallels with Thurnell-Read's (2020) paper and its consideration of the interplay between the economics of drinking and the sociality of alcohol consumption, Gee et al. (2020) argue that a consideration of the micro-level effects of alcohol sponsorship on leisure and sport has been missing, with the overarching focus of much of the literature emphasising the global nature of promotional culture.

We had hoped to include papers from a more culturally and linguistically diverse range of leisure contexts. Freitas et al.'s (2020) paper on alcohol consumption and night time leisure among Brazilian university students reminds us of both the temporal contexts within which particular forms of leisure occur and the ritual function of particular forms of drinking where drinking practices offer a point of rupture with daily life and a period of liminality before entering the adult world. The public nature of drinking by Brazilian students provides a different context to that in which student drinking is more typically done - residential colleges and fraternity/sorority houses - and studied. As such, the contribution from Brazilian colleagues is a welcome expansion of the research literature on drinking, leisure and the night time economy.

\section{Conclusion}

This special issue broaden the geographical, theoretical, and empirical scope of research on alcohol and leisure, sport and tourism. The papers assembled have brought together contributions from sociology, anthropology, tourism studies, sport studies, and alcohol research. The papers variously interrogate methodological issues and innovations in exploring drinking in sport, leisure and tourism, along with theoretical contributions for exploring and re-defining the relationships in and between alcohol, sport, leisure and tourism. The key theme across the contributions is that drinking in leisure, sport and tourism does not take place just anywhere. It is an inherently social act that is subject to a variety of rules and norms regarding who may drink what, when, where, why, how, and with whom.

While it is easy to dismiss drinking as a trivial (or harmful) aspect of leisure, the sociality of drinking - through leisure experiences - serves an important social function. It provides a useful barometer for understanding how people behave while drinking that has broader implications for social scientists and health professionals, among others. By expanding the scope for analysis, considerations in this special issue point to many opportunities for more broadly addressing the diverse social concerns over the leisure, sport tourism and alcohol nexus. 


\section{References}

Bell, D. (2008). Destination drinking: Toward a research agenda on alcotourism. Drugs: Education, Prevention and Policy, 15(3), 291-304.

Carlisle, S., \& Ritchie, C. (2020). Permission to rebel: A critical evaluation of alcohol consumption and party tourism. International Journal for the Sociology of Leisure. https://doi.org/10.1007/s4197 8-020-00061-4.

Collins, R. (2016). Micro-sociology of sport: Interaction rituals of solidarity, emotional energy, and emotional domination. European Journal for Sport and Society, 13(3), 197-207.

Freitas, H., Henriques, S., Uvinha, R., Lusby, C., \& Romera, L. (2020). Alcohol consumption and night time leisure among Brazilian University students. International Journal for the Sociology of Leisure, 3, 389-399.

Gee, S., Batty, R., \& Millar, P. (2020). Alcohol sponsorship and New Zealand regional rugby unions: Crisis point or business as usual? International Journal for the Sociology of Leisure. https://doi. org/10.1007/s41978-020-00071-2.

Graefe, D. A., \& Graefe, A. R. (2020). Gender and craft beer: Participation and preferences in Pennsylvania. International Journal for the Sociology of Leisure. https://doi.org/10.1007/s41978-020-00067 $-\mathrm{y}$.

Ibisworld. (n.d.). https://www.ibisworld.com.au/industry-trends/specialised-market-research-reports/ consumer-goodsservices/craft-beer-production.html.

Palmer, C. (2013). Sport-related drinking; Who's missing? Sport and Alcohol, Special Issue of International Review for the Sociology of Sport. https://doi.org/10.1177/1012690213480353.

Palmer, C., Le Hénaff, Y., Bonnet, C., \& Féliu, F. (2020). Drinking talk among climbers and masters athletes. International Journal of the Sociology of Leisure. https://doi.org/10.1007/s41978-020-00058 $-\mathrm{Z}$.

Spaaij, R., \& Schaillée, H. (2020). Inside the black box: A micro-sociological analysis of sport for development. International Review for the Sociology of Sport. https://doi.org/10.1177/101269022090267 1.

Thurnell-Read, T. (2016). Friendship, identity and sociality. In: Chapter 19 Sage handbook of drug and alcohol studies: Social sciences approaches. London: Sage.

Thurnell-Read, T. (2020). If they weren't in the pub, they probably wouldn't even know each other': Alcohol, sociability and pub based leisure. International Journal for the Sociology of Leisure. https ://doi.org/10.1007/s41978-020-00068-x.

Publisher's Note Springer Nature remains neutral with regard to jurisdictional claims in published maps and institutional affiliations. 